九州大学学術情報リポジトリ

Kyushu University Institutional Repository

Fire Investigation via Analysis of Ignition Characteristics and Carbon Emissions of Fireprone Surface Fuels in Korea

Park, Young-Ju

Chemical Engineering Research Center, Kangwon National University

Lee, Hae-Pyeong

Dept. of Fire \& Emergency Management, Kangwon National University

Lee, Si-Young

Professional Graduate School of Disaster Prevention, Kangwon National University

Park, Gwan-Soo

Department of Forest Resources, Chungnam National University

他

https://doi.org/10.5109/22042

出版情報: 九州大学大学院農学研究院紀要. 57 (1)，pp.7-15，2012-02. Faculty of Agriculture， Kyushu University

バージョン :

権利関係 : 


\title{
Fire Investigation via Analysis of Ignition Characteristics and Carbon Emissions of Fire-prone Surface Fuels in Korea
}

\author{
Young-Ju PARK' ${ }^{1}$ Hae-Pyeong LEE ${ }^{2}$, Si-Young LEE ${ }^{3}$, \\ Gwan-Soo PARK ${ }^{4}$ and Shoji OHGA*
}

\author{
Laboratory of Forest Resources Management, Division of Forest Environmental Sciences, \\ Department of Agro-Environmental Sciences, Faculty of Agriculture, \\ Kyushu University, Fukuoka 811-2415, Japan \\ (Received September 16, 2011 and accepted November 9, 2011)
}

\begin{abstract}
This study focuses on the identification of ignition characteristics and carbon discharge resulting from combustion of surface fuels vulnerable to forest fire. Four withered surface fuels, including dead leaves and cones of Pinus densiflora, dead leaves of Quercus variabilis, and Castenea crenata burs; and six biofuel herbs, including Agsstache rugosa, Oplismenus undulatifolius, Pueraria thunbergiana, Cirsium japonicum var. ussuriense, Festuca ovina L., and Osmundaceae were selected for analysis. Also, monthly carbon emissions (Jun. - Oct. 2008) from Festuca ovina were analyzed.

As a result of tests, it was confirmed that dead leaves and cones of $P$. densiflora and $C$. crenata burs were instantly ignited with flame, which lasted quite a while. The total $\mathrm{CO}_{2}$ and $\mathrm{CO}$ emissions from the 10 different kinds of surface fuels analyzed on this study were 28-98 g and 0.76-4.08 g per $50 \mathrm{~g}$ of each fuel, respectively, indicating that the amount of carbon emissions vary depending on the type of fuel. The results also demonstrated that there is a great difference between withered fuels and biofuels in terms of carbon emissions. More specifically, the four withered types of fuels, compared to the six biofuel herbs, were found to emit more $\mathrm{CO}_{2}$ and $\mathrm{CO}$. In particular, dead cones of $P$. densiflora emitted more carbon dioxide $\left(\mathrm{CO}_{2}\right)$ and carbon monoxide (CO) than the rest of the surface fuels. Also, the carbon emissions were found high during the period of from August to September. Consequently, in the case of a forest fire, dead cones and leaves of $P$. densiflora are expected to emit up to 3.5 times more $\mathrm{CO}_{2}$ and $\mathrm{CO}$ than the other surface fuels. The area covered with dead leaves and pine cones is thought to have a high risk of ignition, high fire intensity because of relatively long lasting flame, and rapid fire spread. Herbs and living fuels with high moisture content are expected to elucidate the course of fire in that they produce large amount of combustion products such as smoke and carbon discharge resulting from nonflame-ignition.
\end{abstract}

Key words: carbon emission, forest fir, Pinus densiflora

\section{INTRODUCTION}

Over the past 19 years (1991-2009) there were 448 forest fire breakouts in Korea, damaging a total of 2,711 ha forest. The same period has also witnessed 12 cases of large-scale forest fires, each of which destroyed more than 30 ha forest, and mostly occurred in April. The damaged area by the large-scale forest fires were shown very serious being accounted for about $70 \%$ of the total areas damaged during the above period (Lee et al., 2001).

Forest fires usually start from a combustible surface fuel under dry weather conditions. The combustion of fire depends on vertical distribution, moisture content and the amount of fuel. The major factors considered in determining fire risk are ignitibility, combustion characteristics, heat amount and the rapidity of heat release,

${ }^{1}$ Chemical Engineering Research Center, Kangwon National University, Samcheok-Si, Gangwon-Do 245-711, Republic of Korea

${ }^{2}$ Dept. of Fire \& Emergency Management, Kangwon National University, Samcheok-Si, Gangwon-Do 245-711, Republic of Korea

${ }^{3}$ Professional Graduate School of Disaster Prevention, Kangwon National University, Samcheok-Si, Gangwon-Do 245-711, Republic of Korea

${ }^{4}$ Department of Forest Resources, Chungnam National University, Daejeon-Si 305-764, Republic of Korea

* Corresponding Author (E-mail: ohga@forest.kyushu-u.ac.jp) smoke and combustion gases, which are known to have a great impact on the development and spread of forest fire. Thus, the analysis on combustion characteristics of surface fuel is considered as an essential process.

Before a forest fire occurs, forests resorb carbon dioxide, preventing its density in the atmosphere from rising above the carbon-neutral fuel. At the same time, combustion of forest resources during forest fires is a source of greenhouse gas emissions that negatively affect global climate and ultimately lead to global warming. Around the globe, the seriousness of greenhouse gas emissions has been alarmed by internet media. Nevertheless, the research on studying the effects by climate change from forest fire has been rarely done in Korea.

The National Center for Atmospheric Research (NCAR) located in Boulder in the United States had previously reported on the forest fire that swept around California in October 2007 and caused as much greenhouse gases emissions as greenhouse gas emissions from all the power plants and vehicles in the state (Washington Associated Press, 2007). Also, the amount of carbon dioxide $\left(\mathrm{CO}_{2}\right)$ emitted from the 8-day sporadic forest fires in California totaled 8.7 million tons. It was stated that forests absorb greenhouse gases, whereas during a forest fire, forests emit carbon dioxide $\left(\mathrm{CO}_{2}\right)$. Carbon dioxide emissions in a forest fire differ greatly depending on where and when the forest fire occurs. In Alaska, for 
example, the greenhouse gas emissions from a forest fire was shown twice as much as those from combustion of fossil fuels, reaching $27 \%$ of the total emissions in the U.S., being followed by other states of California, Oregon, Idaho, Washington, Louisiana, Montana, Georgia, Alabama, and Florida from $2^{\text {nd }}$ to $10^{\text {th }}$. Further, the recent Greek forest fire, which devastated almost half of the entire nation, raised big concerns that it would increase the amount of greenhouse gas emissions that have been blamed for being the main culprit of the global warming (Washington Associated Press, 2007).

Experts both at home and abroad claim that forest fires may be one of the major causes of greenhouse gas emissions. Unfortunately, however, there has been little research in this field of in Korea and abroad due to lack of investment (Kaufman et al., 1989; Ward et al., 1990; Kauffman et al., 1995; IPCC, 2007).

In Korea, there is an ongoing research to develop a specific coefficient to obtain carbon conversion factors using 12 different plant species in order to estimate the greenhouse gas emissions produced as a result of forest fire (Won et al., 2008). However, the above carbon conversion factors have been obtained based on restricted research on conifers and broad-leaved trees and thus the data may not be reliable. Unfortunately, the statistic data to investigate forest fires has not been constructed yet in Korea and thus there is an urgent need for the construction of the basic data to properly estimate the amount of greenhouse gas emission according to each plant species in the forest. Further, the estimate on forest biomass is still not accurate and the geographical information for the classification of subject areas for greenhouse gas statistics has not been well provided. Thus, there has been hardly a research on the estimation of greenhouse gas emissions.

In order to reduce the amount of greenhouse gas emissions due to forest fires it is essential to conduct a systematic fire investigation toward the identification of the exact causes of forest fires and taking suitable preventive measures against expected forest fires. More specifically, the process of forest fire investigation should not be limited to finding out the cause of ignition itself but also include other functions to verify the process throughout fire extinction and reveal the origin of fire, the cause of fire spread, and the causes of casualties and damages. To access this systematic and scientific method, all the data collected through fire occurrence must be put under complete analysis (NFPA 921, 2011). This is indeed essential for successful fire investigation and enables to provide an advisable systematic and analytic process. In this regard, for the analysis of the entire process of fire breakout, it is necessary to take into considerations of fire characteristics based on the data obtained from real combustion experiments on combustibles, and for this, there will be needed sufficient data on combustion characteristics. In addition, for an accurate analysis of forest fire behavior, additional information of topography and climate, and the change of forest combustibles need to be studied. Herbs and plantlets are surface combustibles that have a significant influence on fire spread.
One of the factors on this combustible regarding fire spread is the degree of its dryness. Green grass with high moisture content can serve as a fire wall. However, during the period when there is a frequent forest fire, plants dry up or stems and leaves of vegetation get deprived of water, thereby increasing their flammability. During this period, the ground-covering grass will be readily inflammable. A great portion of dry grass will be the fastest surface combustibles (NFPA 921, 2011). Consequently, the bulk of grass and its combustion characteristics should be identified through real scale combustion experiments.

Accordingly, this study aims at offering the essential basic data for forest fire investigation and for the estimate of greenhouse gas emissions by verifying fire characteristics via analysis of moisture rate and ignition characteristics, and carbon emissions by various surface fuels.

\section{MATERIALS AND METHODS}

\section{Fuel Selection and Measurement of Moisture Content}

Surface fuels were chosen as a subject $P$. densiflora and $Q$. variabilis were selected as they are the representatives of Pineceae and broad-leaved trees. Also, $C$. crenata and herbs as a raw fuel were added because these species are distributed abundantly in Samcheok area of Gangwon province in Korea. For consistency reason in selecting fuels, surface fuels were chosen when herbs were in a leaf developing period (Oct. - Nov.) The average temperature and relative humidity of Oct. and Nov. were $8.45^{\circ} \mathrm{C}$ and $35.05 \%$, respectively. The withered fuels were collected in April and May, when there is a frequent forest fire. On the other hand, herbs were collected in October and November.

Among surface fuels, 6 biofuel herbs vegetating on the ground surface \{Osmundaceae, Agastache rugosa (Fisch. et Meyer) O. Kuntze, Oplismenus undulatifolius (Ard.) Roem. \& Schult., Pueraria thunbergiana (Siebold \& Zucc.) Benth., Cirsium japonicum var. ussuriense Kitamura and Festuca ovina L. (Sheep's fescue)\} and 4 withered surface fuels (dead leaves and cones of Pinus densiflora Siebold \& Zucc., dead leaves of Quercus variabilis Bl., and Castanea crenata Siebold \& Zucc. burs) were selected. Fuels were collected within a $100 \mathrm{~m}^{2}$ area in a forest fire-prone zone (Lee et al., 2004; Lee et al., 2005) in Samcheok, Gangwon province in Korea. The fuels were collected during the period from October 2009 to November 2009, on the day following a 5-day fine weather streak. Festuca ovina was selected since when experimented in advance, its carbon discharge was higher than other specimen and its moisture content was lower. To analyze monthly carbon emissions, $F$. ovina was collected monthly during the period from Jun. 2009 to Oct. 2009. Each fuel collected was used unchanged for the purposes of preserving the same fuel conditions as in a real forest fire.

Each fuel collected was used unchanged for the purposes of preserving the same fuel conditions as in a real forest fire. Moisture content of the fuels used was measured. To measure the moisture content, $200 \mathrm{mg}$ of each 
fuel material was dried for over 24 hours in a drying oven set at $105^{\circ} \mathrm{C}$, and weighed, until the moisture content reached a predetermined level. As a reference for the moisture content measurement, weights of samples were measured every 4 hours until there was a change in weight by less than 0.1 percent. Then, Formula 1 was used to yield the result (Gang et al., 2002; Sim et al., 1994). In Formula 1, MC is moisture content (\%); $\mathrm{W}$ is the weight of a sample before drying (g); and $\mathrm{W}_{0}$ is the weight of a sample after drying, marked as percentage against the weight of wood containing no moisture. The results obtained were mean values of the three measurements.

$$
M C(\%)=\frac{W-W_{0}}{W_{0}} \times 100(\%)
$$

\section{Combustion Experiment}

The combustion experiment to analyze carbon emissions and ignition characteristic of the surface fuels was performed by using British FTT's Dual Cone Calorimeter (ISO 5660-1, 2002). Specific experimental conditions are summarized in Table 1 . To measure carbon emissions, a total amount of emissions of carbon dioxide $\left(\mathrm{CO}_{2}\right)$ and carbon monoxide (CO) from $50 \mathrm{~g}$ of each fuel burned by exposing them to radiant heat was measured. A total of three measurements were averaged to obtain the resulting values upon completing the experiment when there was no more change in weight loss. For a radiant heat, $50 \mathrm{~kW} / \mathrm{m}^{2}$ radiant heat was used as suggested by ISO 5660-1 and is reported as "fully develop", which is the most similar step to real fire situation consisting of a 4 serial steps of fire scenario (ignition, growth, fully develop, decay) (NFPA 921, 2011).

Table 1. Experimental Conditions of British FTT' Dual Cone Calorimeter

\begin{tabular}{cc}
\hline Items & Cone Calorimeter \\
\hline Sample Holder Size (mm) & $100 \times 100$ \\
Sample Weight $(\mathrm{g})$ & 50 \\
Heat Flux $\left(\mathrm{kW} / \mathrm{m}^{2}\right)$ & 50 \\
Test Duration (s) & Time required until there is no more \\
Materials Used & decrease in weight \\
\end{tabular}

\subsection{Principle of Experiment}

The principle of the experiment is that the heat amount from a combustion system is related to the amount of oxygen exhausted from air. Most of combustible materials emit $13.1 \mathrm{MJ}$ by $1 \mathrm{~kg}$ of exhausted oxygen. For the generation of heat, we need a certain amount of oxygen being eliminated from emission flow. By adding $\mathrm{CO}$ and $\mathrm{CO}_{2}$ thereto, more accurate value can be acquired considering incomplete combustion (ISO 5660-1, 2002).

\subsection{Method of Experiment}

The procedure is that all transducers of Heat Flux

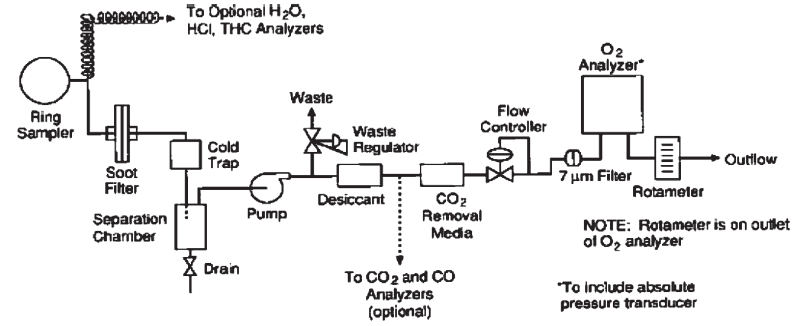

Fig. 1. Gas Analyzer Instrument.

Meter for radiant heat, Mass Flow Meter (MFM) for measuring methane, Differential Pressure Transducer (DPT) for pressure, Gas Analyzer for $\mathrm{O}_{2}, \mathrm{CO}$, and $\mathrm{CO}_{2}$, and Load Cell for mass decrease by combustion should be corrected first. Then, $60 \mathrm{~s}$ data is collected to obtain an early oxygen value. After collecting standard data, a sample on the sample holder placed on the apparatus for mass measurement is inserted into ignition equipment. The test begins after clearing the closed the shutter system. Ignition equipment helps ignition of a gas generated after pyrolyzing. Once the sample is ignited, the equipment is removed and the experiment is on going further.

The gas from combustion goes into a gas analyzer with a constant flux $(3.5 \mathrm{~L} / \mathrm{min})$ by pumping and this procedure is presented in Fig. 1. All measuring instruments calculate factors on obtaining the data in real time. All three tests were conducted in the same manner.

\section{RESULTS AND DISCUSSION}

In this study, the results of moisture content characteristics and ignition characteristics, both of which play a key role to forest fire spread, and that of carbon emissions characteristics of surface fuels by incomplete combustion are as follows.

\section{Moisture Content and Ignition Characteristics}

Figure 2 demonstrates moisture content characteris-

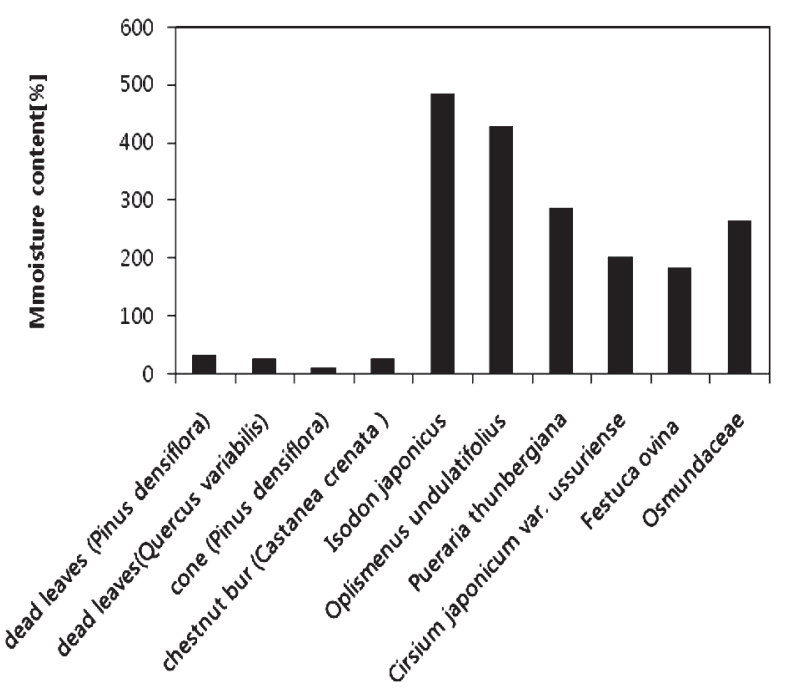

Surface fuels

Fig. 2. Characteristics of Moisture Content of Various Fuels. 
tics of the 10 different kinds of surface fuels used in the study. Withered fuel, including dead leaves and cones of Pinus densiflora, dead leaves of Quercus variabilis, and Castanea crenata burs were found to contain 9-24\% of moisture in comparison to $181-484 \%$ of moisture contained in biofuel herbs. This indicates a significant difference in moisture content between the withered surface fuels and biofuels. As for the surface fuels with the lowest moisture content, dead pine cones of Pinus densiflora and Castanea crenata burs were found to contain 9-10\% of moisture, while dead pine leaves of Pinus densiflora and leaves of Quercus variabilis were found to contain 21-24\%. Also, Festuca ovina was found to contain $181 \%$ of moisture, the lowest level among the biofuel herbs. The results are presented in Table 2.

The degree of dryness of fuels is affected by relative humidity of air. The moisture content of fuels varies according to the fuels' size, density and sediment conditions. The degree of dryness has a significant influence on ignition characteristics, and is closely associated with combustibility according to moisture content (Gang et al., 2002; Yim et al., 2007).

Furthermore, moisture content plays an important role to decide ignitibility and the rapidity of fire spread: the high degree of dryness leads to high ignitibility and severe fire intensity. The plants with green leaves or high

Table 2. Moisture Content Percentage of Various Fuels

\begin{tabular}{|c|c|c|}
\hline & Species & $\begin{array}{c}\text { Moisture } \\
\text { Content (\%) }\end{array}$ \\
\hline \multirow{2}{*}{$\begin{array}{c}\text { Dead } \\
\text { Leaves }\end{array}$} & Pinus densiflora & 24.01 \\
\hline & Quercus variabilis & 20.70 \\
\hline Cones & Pinus densiflora & 10.02 \\
\hline Burs & Castanea crenata & 9.02 \\
\hline \multirow{6}{*}{$\begin{array}{l}\text { Living } \\
\text { Leaves }\end{array}$} & Isodon japonicus & 483.96 \\
\hline & Oplismenus undulatifolius & 427.45 \\
\hline & Pueraria thunbergiana & 285.81 \\
\hline & Cirsium japonicum var. ussuriense & 201.35 \\
\hline & Festuca ovina & 180.63 \\
\hline & Osmundaceae & 264.14 \\
\hline
\end{tabular}

moisture content have difficulty igniting and burn slowly, evaporating the moisture in them and absorbing the heat. Once the moisture is gone, the temperature goes up and finally reaches ignition temperature. The moisture content of combustibles depends on the types and conditions of plants, the degree of exposure to the sun, weather, and topography. In the conclusion, the surface fuels with low moisture rate such as leaves and pine cones are considered to have fast ignition and fire spread. (NFPA 921, 2011).

\section{Ignition Characteristics}

Table 3 shows ignition characteristics of 10 different kinds of surface fuels. The dead leaves of $P$. densiflora and $Q$. variabilis were shown to ignite in $9 \mathrm{~s}$ and $28 \mathrm{~s}$, and cones of $P$. densiflora and C. crenata burs $28 \mathrm{~s}$ and $15 \mathrm{~s}$, respectively. All the six kinds of herbs were not ignited. As for flame duration time after ignition, the flame of the dead leaves of $P$. densiflora and $Q$. variabilis lasted 936s and $1004 \mathrm{~s}$, and cones of $P$. densiflora and C. crenata burs lasted 558s and 507s. The dead leaves of $P$. densiflora were ignited most rapidly and the dead leaves of $Q$. variabilis showed the longest flame duration. Therefore, the dead leaves, cones and burs which have low moisture content, are likely to have a high ignition risk. This result is thought that the fire spread rapidly throughout the area whose surface is covered with a lot of dead leaves and cones.

In general, dead leaves, including $P$. densiflora and Q. variabilis, pine cones of $P$. densiflora, burs of $C$. crenata with low moisture content underwent flame ignition, whereas herbs, including A. rugosa, O. undulatifolius, Pu. thunbergiana, Ci. japonicum var. ussuriense, $F$. ovina and Osmundaceae with high moisture content did not. Withered leaves of $P$. densiflora demonstrated fastest flame ignition time (9 seconds) and longest flame duration (936 seconds). These findings indicate that the drier the fuels, the faster the ignition. Table 4 shows correlations between moisture content and combustibility (Gang et al., 2002; Kim et al., 2006). Table 3 demonstrates that the lower the moisture content, the higher the ignition risk. Regarding combustibility, cones of $P$. densiflora and burs of $C$. crenata (9-10\% of moisture content) were dry enough to be ignited by match fire,

Table 3. Ignition Characteristics of Various Surface Fuels

\begin{tabular}{cccc}
\hline & Species & Ignition time (s) & Extinction time (s) \\
\hline \multirow{2}{*}{$\begin{array}{c}\text { Dead } \\
\text { Leaves }\end{array}$} & Pinus densiflora & 9 & 936 \\
\cline { 2 - 4 } Cones & Quercus variabilis & 28 & 1004 \\
\hline Burs & Pinus densiflora & 28 & 558 \\
\hline \multirow{2}{*}{ Living } & Castanea crenata & 15 & 507 \\
\cline { 2 - 4 } Leaves & Oplismenus undulatifolius & No Ignition & No Ignition \\
\cline { 2 - 4 } & Puerarian thunbergiana & No Ignition & No Ignition \\
\cline { 2 - 4 } & Festuca ovina & No Ignition & No Ignition \\
\cline { 2 - 4 } & Osmundaceae & No Ignition & No Ignition \\
\hline
\end{tabular}


Table 4. Correlations between Moisture Content and Combustibility of Forest Fuels

\begin{tabular}{cc}
\hline $\begin{array}{c}\text { Moisture Content } \\
\text { (MC) (\%) }\end{array}$ & Combustibility \\
$26<$ & None \\
$19-25$ & Very low \\
$14-18$ & Low (Bonfire has potential risk) \\
$11-13$ & Moderate (Match fire has potential risk) \\
$8-10$ & Dangerous (Match fire is always risky) \\
$2-7$ & Highly potential risk \\
& (Every heat of fire has potential risk) \\
\hline
\end{tabular}

whereas dead leaves (20-24\% of moisture content) were found very low in combustibility.

Forest inflammable material is ignited at various temperature conditions depending on moisture content, oil content and mineral content. Inflammability differs depending on the size, characteristics, oil and mineral content, weather condition, topography and direction, etc. When fuels are exposed for a quite long period, the combustible is apt to ignite and spread with ease. On the contrary, the combustible in the wet weather or in the shadow need a higher temperature condition for ignition because this combustible absorbs moisture (NFPA 921, 2011).

Consequently, withered fuels have high degree of ignitibility, and so the forest fire will spread with rapidity. On the other hand, herb which is a raw fuel is not ignited with flame. Combustion products generated are thought to the result of incomplete combustion, which leads to ignition without flame. It is thought that the passage of fire and the severances of fire are estimated by the trail of soot, the result of incomplete combustion.

\section{Carbon Dioxide Emission Characteristics}

Figure 3 shows carbon dioxide $\left(\mathrm{CO}_{2}\right)$ emissions from the ten fuels. The dead leaves of $P$. densiflora and $Q$. variabilis emitted $77.5193 \mathrm{~g}$ and $51.7427 \mathrm{~g}$, and cones of $P$. densiflora and C. crenata burs $97.9673 \mathrm{~g}$ and 67.9895 g, respectively. A. rugosa emitted $28.4170 \mathrm{~g}, O$. undulatifolius $34.6010 \mathrm{~g}, \mathrm{Pu}$. thunbergiana $39.1740 \mathrm{~g}$, Ci. japonicum var. ussuriense $40.5110 \mathrm{~g}, F$. ovina L. $48.2236 \mathrm{~g}$, and Osmundaceae $39.9731 \mathrm{~g}$, respectively.

Regarding the total carbon dioxide emissions from $50 \mathrm{~g}$ of each selected fuel, the results varied significantly within the range of 28-98 g. Four withered fuels with low MC - dead leaves and cones of $P$. densiflora, dead leaves of $Q$. variabilis, and C. crenata burs, emitted about $52-98 \mathrm{~g}$ of carbon dioxide $\left(\mathrm{CO}_{2}\right)$. Six herb biofuels emitted about $28-48 \mathrm{~g}$ of carbon dioxide. Particularly, dead pine cones of $P$. densiflora were found highest in carbon dioxide emissions (98g), followed by dead pine leaves (78 g). Agastache rugosa and O. undulatifolius were found relatively low in $\mathrm{CO}_{2}$ emissions - they emitted $28 \mathrm{~g}$ and $35 \mathrm{~g}$ of carbon dioxide, respectively.

Thus, in case of a forest fire, dead pine cones and leaves of $P$. densiflora could emit 3.5 times more $\mathrm{CO}_{2}$ than the other surface fuels. This is summarized in Table 5. Also, dead leaves of coniferous pine tree species (Jung et al., 2002), known to be most vulnerable to forest fires, and the dead leaves of deciduous $Q$. variabilis species, known to be resistant to fire, emitted $78 \mathrm{~g}$ and $52 \mathrm{~g}$ of carbon dioxide $\left(\mathrm{CO}_{2}\right)$, respectively. These findings indicate that dead pine leaves emit 1.5 times more $\mathrm{CO}_{2}$ than $Q$. variabilis leaves. The difference in the emission levels results from the composition ratios of major and minor components of each fuel. The main components include cellulose and lignin. Previous reports showed that deciduous broad-leaved trees' hemicelluloses consist mostly of xylan, while coniferous trees' hemicellulose is composed of galacto-glucomannan (Sim et al., 1994; Shin et al., 1993). Also, lignin consists of phenyl propane as the basic substance, and coniferous lignin is mostly composed of guaiacyl lignin while its deciduous counterpart consists of guaiacyl lignin and syringyl lignin. It was also found that terpenoid component in normal and damaged leaves and pine cones were significantly different (Choi, et al., 1994).

In studying the pyrolysis product of the major components, after cellulose is pyrolyzed on the temperature of $300^{\circ} \mathrm{C}-500^{\circ} \mathrm{C}$, levogluconic acid f furfural f furane $\cdot 2-$ methlfurane are produced in a low temperature, and ace taldehyde $\cdot$ propionaldehyde $\cdot$ acrolein $\cdot$ acetone, which do

Table 5. Total Amount of Carbon Dioxide $\left(\mathrm{CO}_{2}\right)$ and Carbon Monoxide (CO) Emissions of Various Surface Fuels

\begin{tabular}{cccc}
\hline & Species & $\mathrm{CO}_{2}$ yield $(\mathrm{g})$ & CO yield $(\mathrm{g})$ \\
\hline \multirow{2}{*}{$\begin{array}{c}\text { Dead } \\
\text { leaves }\end{array}$} & Pinus densiflora & 77.5193 & 3.2357 \\
\cline { 2 - 4 } Cone & Quercus variabilis & 51.7427 & 3.6052 \\
\hline Burs & Pinus densiflora & 97.9673 & 4.0814 \\
\hline \multirow{2}{*}{$\begin{array}{c}\text { Live } \\
\text { Leaves }\end{array}$} & Castanea crenata & 67.7895 & 3.7895 \\
\cline { 2 - 4 } & Isodon japonicus & 28.4170 & 0.8030 \\
\cline { 2 - 4 } & Oplismenus undulatifolius & 34.6010 & 0.9720 \\
\cline { 2 - 4 } & Puersium japonicum var. ussuriense & 39.1740 & 1.1620 \\
\cline { 2 - 4 } & Festuca ovina & 40.5110 & 1.0410 \\
\hline
\end{tabular}


not have annulation, rise at high temperature. When lignin is pyrolyzed, phenol · vanillin · p-cresol · gallic acid · syringa aldehyde, which are aromatic compounds, are created. Compared to cellulose, lignin has more resistant to pyrolysis and more charcoal. Hemi-cellulose produces $\mathrm{CO} \cdot \mathrm{CO}_{2} \cdot$ methane $\cdot$ ethane $\cdot$ acetylene $\cdot$ ethylene $\cdot$ formal dehyde $\cdot$ acetaldehyde $\cdot$ H2 furfural · methylfurfural when pylolyzed. In sum, although the specific content of each component in carbon compounds could not be determined, pine cones and dead leaves were found high in pentosan, holocellulose and lignin contents, leading to organic polymers formed by carbon, oxygen and hydrogen, and monoterpene component is assumed to serve greatly for perfect combustion (Shim, et al., 1994).

Consequently, we do not know the accurate amount of carbon compounds, but the cones and dead leaves of Pinus densiflora has lots of pentosan, holocellulose and lignin, which is thought to lead to complete combustion from monoterpene because carbon, oxygen and hydrogen form polymer.

The indicator of direction of forest fire spread remains on partly combusted fuels and incombustible material and is revealed by damage, carbonization pattern, discoloration and condition of non-combusted material. Partly combusted material is sorted into complete and incomplete combustible material and this type of combustion shows the combustion environment of fuels including combustion characteristics of combustibles (NFPA 921, 2011).

Thus, the analysis of $\mathrm{CO}_{2}$ emissions is thought to be used as basic data for estimating $\mathrm{CO}_{2}$ emission amount as a result of complete combustion and as a tip for estimating combustibility among fuels.

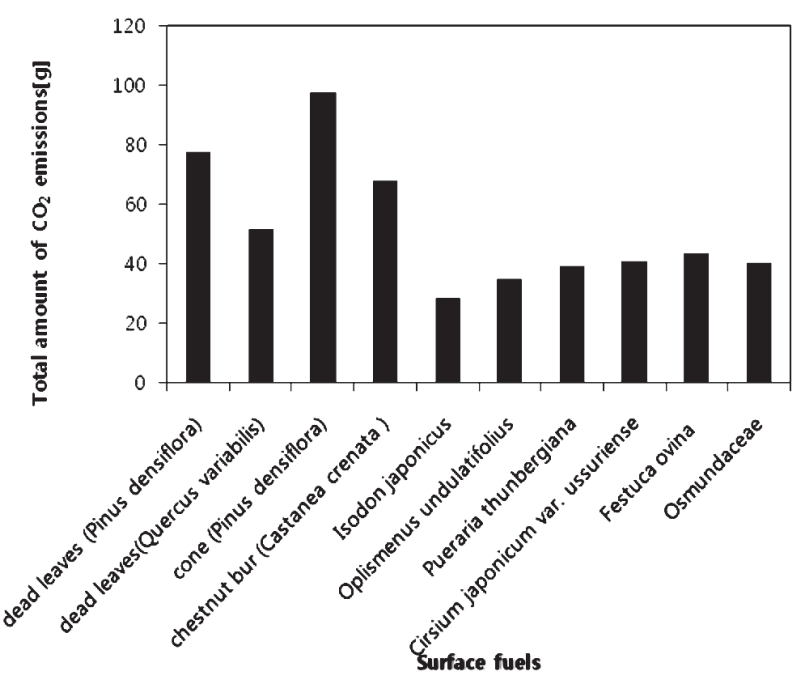

Fig. 3. Total Amount of Carbon Dioxide $\left(\mathrm{CO}_{2}\right)$ Emissions of Various Surface Fuels.

\section{CO Emission Characteristics}

Figure 4 shows CO emissions after combustion of the surface fuels. Figure 3 shows CO emissions after combustion of the surface fuels. The dead leaves of $P$. densiflora and Q. variabilis emitted $3.2357 \mathrm{~g}$, and 3.6052, and cones

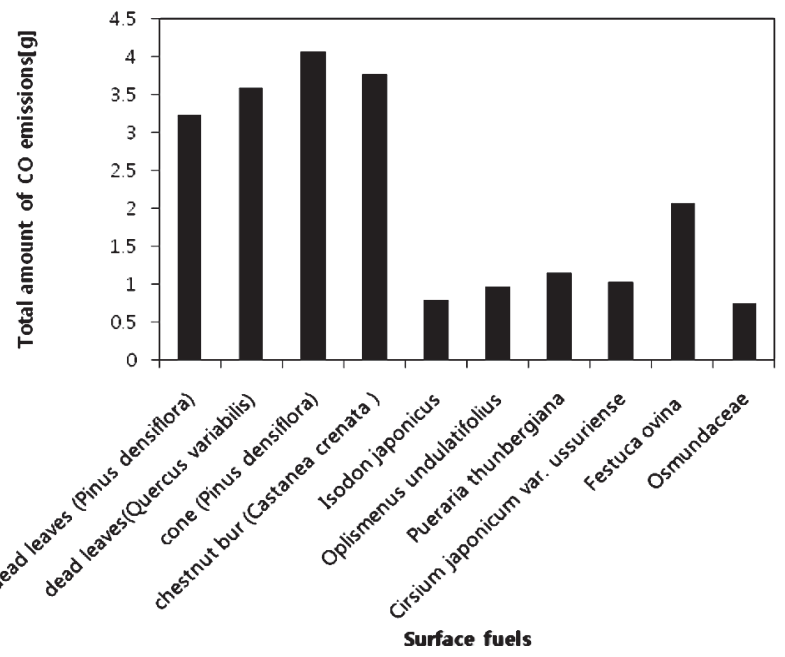

Fig. 4. Total Amount of Carbon Monoxide (CO) Emissions of Various Surface Fuels.

of $P$. densiflora and $C$. crenata burs 4.0814 , and $3.7895 \mathrm{~g}$ respectively. A. rugosa emitted $0.803 \mathrm{~g}, O$. undulatifolius $0.9720 \mathrm{~g}, \mathrm{Pu}$. thunbergiana $1.1620 \mathrm{~g}, \mathrm{Ci}$. japonicum var. ussuriense $1.0410 \mathrm{~g}, F$. ovina L. $2.7297 \mathrm{~g}$, and Osmundaceae $0.7628 \mathrm{~g}$, respectively.

More specifically, $50 \mathrm{~g}$ of each of the surface fuels emitted CO within the range of 3.2357-5.4331 g. Similarly to $\mathrm{CO}_{2}$ emissions, $\mathrm{CO}$ emissions were found high for withered surface fuels. Withered surface fuels, including dead leaves and cones of $P$. densiflora, dead leaves of $Q$. variabilis, and C. crenata burs emitted about 3.2357$4.0814 \mathrm{~g}$ of CO, whereas six biofuel herbs, including $A$. rugosa, O. undulatifolius, $P u$. thunbergiana, Ci. japonicum var. ussuriense, $F$. ovina and Osmundaceae emitted 0.7628-2.7279 g. Carbon monoxide (CO) emissions for surface fuels were found high for $P$. densiflora cones (4.0814 g), C. crenata burs (3.7895 g), leaves of $Q$. variabilis (3.6052 $\mathrm{g}$ ), and leaves of $P$. densiflora $(3.2357 \mathrm{~g})$. These findings are presented in Table 5 .

Carbon monoxide (CO) is generated as a result of imperfect combustion of carbon, or carbon compounds, and oxidation of oil components in trees. Wood oil consists mostly of terpene, which is known to be the main component of coniferous trees (Song et al., 1994; Sim et al., 1993) and pine cones. Pine cones were analyzed to contain 23 types of terpene, whose chemical structure is $\mathrm{C}_{10} \mathrm{H}_{16}$. Monoterpene component is highest among the carbon compounds found in pine cones, and accounts for about $41 \%$ of all compounds (71\%) (Choi et al., 1994; Cho et al., 1997). $\beta$ phellandrene, a monoterpene, accounts for $19 \%$; sabinene and caryophyllen for about 10\%; and other compounds for 6-0.06\% (Choi et al., 1994; Cho et al., 1997; Kang et al., 2002).

According to statistical analyses of the composition of coniferous trees oil, monoterpene, sesquiterpene and oxygenated terpene amount to over 94\% in normal leaves (Kang, et al., 2002). Also, significant differences exist in terpene components in normal and damaged leaves, and pine cones (Choi et al., 1994; Kim et al., 2005). Hence, 
due to differences in the components, component ratios, and contents between normal leaves of biofuels and withered fuels, it is expected that there is a significant difference in carbon emissions between the two types of fuels.

It showed the difference of Carbon emissions is caused by that of reactivity to heat when pyrolyzed. Cellulose reveals different reactivity to heat on crystalline region and amorphous region; when crystalline cellulose was pyrolyzed, acetaldehyde · acetone, etc. are produced. At the beginning of pyrolysis, there comes a lot of furfura, but on the process the amount of acetaldehyde - acetone increase. When amorphous cellulose was pyrolyzed, from the beginning more furfural and furane come out than the other. Lignin has different thermal characteristics and is pyrolyzed gradually during wide temperature range. When Hemi-cellulose is pyrolyzed, gas is produced more than tar, and like cellulose, a large amount of water-soluble material of the dry-distillation comes out but levogluconic acid is not produced unlike cellulose (Shim, J. S. et al., 1994).

Carbon is one of 6 gases $\left(\mathrm{CO}_{2}, \mathrm{CH}_{4}, \mathrm{~N}_{2} \mathrm{O}, \mathrm{HFCs}\right.$, PFCs, $\mathrm{SF}_{6}$ ) which are regulated by Kyoto Protocol and is regarded as an important greenhouse gas recently. Lethal concentration (LC) in air is over 100,000 ppm and 1,000 ppm CO may cause disturbance of consciousness. However, as forest fire does not occur in a confined room the damage from $\mathrm{CO}$ and $\mathrm{CO}_{2}$ is thought to be severe. The emission of $\mathrm{CO}$ is thought to be used as a tip for estimating combustibility among fuels as well.

\section{Seasonal Characteristics of Carbon Emissions}

Fuel collection from herbs whose leafing season starts around Jun. is possible until October. Therefore, from Jun. to Oct. fuels were collected every month for the purposes of a combustion experiment. Figure 5 shows $\mathrm{CO}_{2}$ emissions after combustion of the surface fuels.

Prior to the combustion experiment, MC (moisture content) of samples was measured: $144.04 \%$ in Jun., $186.51 \%$ in Jul., $180.63 \%$ in Aug., 357.88\% in Sep., $232.09 \%$ in October. Moisture content showed the lowest in June and the highest in September, and the gap of moisture content between the two was wide. Thus, June is the most dangerous season for ignition of those five months period.

Regarding ignition characteristics, flame ignition did not happen during the entire period. These findings are presented in Table 6.
Figure 5 shows the results of amount of monthly (Jun. - Oct.) carbon emissions for Festuca ovina. As we can see in the figure, $\mathrm{CO}_{2}$ emission is $43.5658 \mathrm{~g}$ in Jun., $25.6053 \mathrm{~g}$ in July, $52.3056 \mathrm{~g}$ in Aug., $49.2958 \mathrm{~g}$ in Sep., $48.2236 \mathrm{~g}$ in Oct. and CO emission is $2.0856 \mathrm{~g}$ in Jun., $0.3185 \mathrm{~g}$ in Jul., $3.0130 \mathrm{~g}$ in Aug., $2.5502 \mathrm{~g}$ in Sep, $2.7279 \mathrm{~g}$ in Oct.

Festuca ovina $\mathrm{CO}_{2}$ and $\mathrm{CO}$ emissions were slightly higher in Aug. and Sep., indicating seasonal differences in carbon emissions. Although specific differences that are dependent on content and composition were not clarified, they seem to be attributable to seasonally different ratios of major and minor components (Ahn, 1993). Carbon oxides result from perfect or imperfect combustion at a higher temperature after major and minor components are pyrolyzed into organic aldehyde and organic acids (Lee, 2005).

Therefore, the fact that herbs, which are raw materials, were not ignited with flame shows that in spite of some differences of moisture content among months, as they have high degree of moisture content, they are thought to have been ignited without flame. Ignition without flame leads to incomplete combustion because the material is ignited without flame, and lots of moisture prevents the temperature from rising. Incomplete combustion leaves a clue behind how the material was burned after fire occurs (NFPA 921, 2011). Thus it is possible to presume that the severances and the direction of fire depend on the wake of soot owing to imperfect combustion. Although the gaps of margin of error are wide, as the samples of herb were collected between Jun. and Oct. which are not the period of forest fire, we

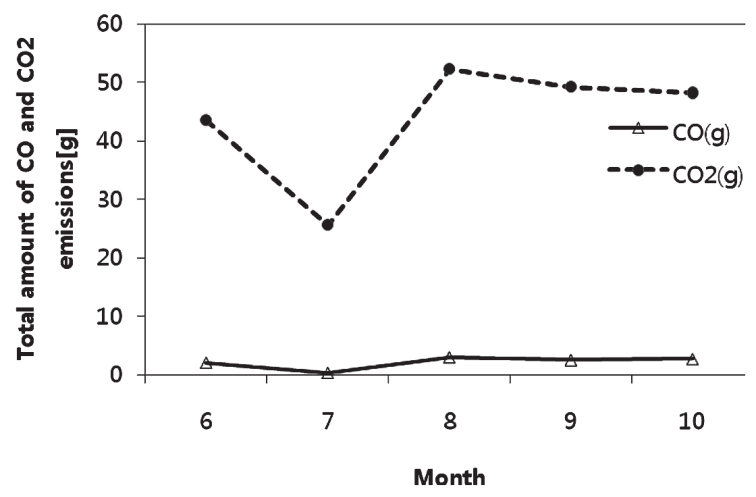

Fig. 5. Amount of Monthly Carbon Emissions for Festuca ovina.

Table 6. Amount of Monthly Carbon Emissions by Festuca ovina

\begin{tabular}{cccccc}
\hline Month & $\begin{array}{c}\text { Moisture } \\
\text { Contents (\%) }\end{array}$ & Ignition Time (s) & $\begin{array}{c}\text { Extinction Time } \\
(\mathrm{s})\end{array}$ & $\begin{array}{c}\mathrm{CO}_{2} \text { yield } \\
(\mathrm{g})\end{array}$ & $\begin{array}{c}\text { CO yield } \\
(\mathrm{g})\end{array}$ \\
\hline Jun. & 144.04 & No Ignition & No Ignition & 43.5658 & 2.0856 \\
Jul. & 186.51 & No Ignition & No Ignition & 25.6053 & 0.3185 \\
Aug. & 180.63 & No Ignition & No Ignition & 52.3056 & 3.013 \\
Sep. & 357.88 & No Ignition & No Ignition & 49.2985 & 2.5502 \\
Oct. & 232.09 & No Ignition & No Ignition & 48.2236 & 2.7279 \\
\hline
\end{tabular}


concentrate on the study of the change of combustion characteristics by month.

\section{CONCLUSION}

This study shows the following conclusion after combustion experiments on surface fuels prone to forest fire were conducted.

1) Regarding moisture content characteristics, withered fuel, including dead leaves and cones of Pinus densiflora, dead leaves of Quercus variabilis, and Castanea crenata burs were found to contain 9-24\% of moisture in comparison to $181-484 \%$ of moisture contained in biofuel herbs. Therefore, dead surface fuels are apt to be combustible owing to low moisture content. On the other hand, dead leaves and cones are thought to be ignited with rapidity and to process the fire spread quickly.

2) Regarding ignition characteristics of the surface fuels. The dead leaves of $P$. densiflora and $Q$. variabilis were ignited in $9 \mathrm{~s}$ and $28 \mathrm{~s}$, and cones of $P$. densiflora and $C$. crenata burs $28 \mathrm{~s}$ and $15 \mathrm{~s}$, respectively. They all were ignited with rapidity comparatively. All the six kinds of herbs were not ignited. Therefore, the dead fuels revealed the high possibility of ignition risk. Consequently, withered fuels have high degree of ignitibility, and so the forest fire will spread with rapidity. On the other hand, herb which is a biomass fuel is not ignited with flame. Combustion products generated are thought to the result of incomplete combustion, which leads to ignition without flame. It is thought that the passage of fire and the severances of fire are estimated by the trail of soot, the result of incomplete combustion.

3) Regarding $\mathrm{CO}_{2}$ emission characteristics for surface fuels, total $\mathrm{CO}_{2}$ emissions from $50 \mathrm{~g}$ of each sample varied significantly within the range of $28-98 \mathrm{~g}$. In particular, four withered fuels with low MC, including dead leaves and cones of $P$. densiflora, dead leaves of $Q$. variabilis, and C. crenata burs, and six herb biofuels emitted 52-98 $\mathrm{g}$ and 28-48 $\mathrm{g} \mathrm{CO}_{2}$, respectively. Above all, pine cones of $P$. densiflora emitted more $\mathrm{CO}_{2}$ (98g) than the other samples of the withered fuels and biofuels tested in the study. Thus, in case of a forest fire, pine cones and needles may emit up to 3.5 times more of carbon dioxide than the other surface fuels. The dead leaves of coniferous pine trees, known to be most vulnerable to forest fires, emitted about $78 \mathrm{~g}$ of $\mathrm{CO}_{2}$, while the leaves of deciduous broad-leaved $Q$. variabilis species, known to be fireproof, emitted about $52 \mathrm{~g}$ of $\mathrm{CO}_{2}$. This implies that dead pine needles will emit 1.5 times more $\mathrm{CO}_{2}$ than dead Oriental oak leaves. Thus, the analysis of $\mathrm{CO}_{2}$ emissions is thought to be used as basic data for estimating $\mathrm{CO}_{2}$ emission amount as a result of complete combustion and as a tip for estimating combustibility among fuels.

4) Regarding $\mathrm{CO}$ emissions, total $\mathrm{CO}$ emissions from $50 \mathrm{~g}$ of each surface fuel varied within the range of 3.23575.4331g. As with $\mathrm{CO}_{2}$, CO emissions were found higher in withered surface fuels. Four withered fuels, including dead leaves and cones of $P$. densiflora, dead leaves of $Q$. variabilis, and $C$. crenata burs and six biofuel herbs, including A. rugosa, O. Undulatifolius, $P u$. thunbergiana, $C i$. japonicum var. ussuriense, F. ovina and Osmundaceae emitted 3.2357-4.0814 g and $0.7628-2.7279 \mathrm{~g}$ of CO respectively. Pine cones of $P$. densiflora emitted more CO (4.0814 g) than the other surface fuels, followed by $C$. crenata burs (3.7895 g), leaves of $Q$. variabilis (3.6052 g) and leaves of $P$. densiflora (3.2357g). Pine cones of $P$. densiflora are relatively high in $\mathrm{CO}$ emissions. This could be related to high levels of terpene they contain. However, as forest fire does not occur in a confined room the damage from $\mathrm{CO}$ and $\mathrm{CO}_{2}$ is thought not to be severe. The emission of $\mathrm{CO}$ is thought to be used as a tip for estimating combustibility among fuels as well.

5) To analyze seasonal carbon emissions, Festuca ovina's example was used, and its carbon emissions on a monthly basis from Jun. to Oct. were measured. It was found that $\mathrm{CO}_{2}$ and $\mathrm{CO}$ emissions were slightly higher in Aug. and Sep., indicating that there are seasonal differences in carbon emissions. These differences are probably due to seasonally different ratios of major and minor components that are related to changes in the content of carbon compounds during $F$. ovina growth periods. Although content-specific differences could not be determined, the seasonal difference in carbon emissions seems to be related to cellulose, the major component. Therefore, the fact that herbs, which are raw materials, were not ignited with flame shows that in spite of some differences of moisture content among months, as they have high degree of moisture content, they are thought to have been ignited without flame. Although the gaps of margin of error are wide, as the samples of herb were collected between Jun. and Oct. which are not the period of forest fire, we concentrate on the study of the change of combustion characteristics by month.

6) As surface fuels, which are prone to fire, are a key factor for fire spread, this study is conducted on the relationship of moisture content and ignitibility, and carbon emission of surface fuels. Therefore, this study is thought to be used as basic data to cope with global climate change and fire investigation.

\section{ACKNOWLEDGEMENTS}

This research was supported by Basic Science Research Program of the National Research Foundation of Korea (NRF) funded by the Ministry of Education, Science and Technology (2011-0005926).

\section{REFERENCES}

Ahn, W. Y. 1993 'Seasonal variation of monoterpene composition in needle oils from Korean red pine (Pinus densiflora), Korean white pine ( $P$. Koraiensis), and Pitch pine (P. rigida)'. Journal of the Korean forest engineering, No. 13(1): 29-36 
Cho, J. H., B. H. Hwang, , H. J. Lee, , J. L. Zhao, , H. Y. Kang, and S. H. Yoo 1997 'Special component analysis of pine needles for search of new functional materials'. Journal of the Korean society of wood science technology, wood engineering conference of autumn, pp. 130-135

Choi, C. I. B. and B. H. Hwang 1994 'Original articles: terpenoid analysis of the normal, damaged needle and pinecone in Pinus densiflora'. The Korean society of wood science technology, No. 22(1): 72-79

Washington Associated Press 2007 California forest fire, Large quantity emission of greenhouse gases emission'. Younhap News Agency, http://www.2006un.org/8756, (Accessed on 2 November 2007)

ISO 5660-1 2002 Reaction to fire part 1, rate of heat release from building products (Cone Calorimeter).

Jung J. S., B. D. Lee and H. H. Kim 2002 'Estimation of Pinus densiflora: stand damage grades for Samcheok forest fire area using GIS and discriminant analysis'. Journal of the Korea association of geographic information studies, No. 91(3): $355-361$

Kang J. Y., S. W. Kim, Y. C. Kim, J. G. Kim, J. S. Kim, S. C. Park, Y. G. Park, S. W. Lee, S. Y. Lee, Y. S. Lee, C. H. Lee, H. H. Lee, S. B. Chung, and J. O. Hyun 2002 Forest environmental preservation. Hyangmoonsa, pp. 34-58 (in Korea)

Kim D. H., M. B. Lee, Y. H. Kang and S. Y. Lee 2006 'The analysis of forest fire hazard of a surface fuel through Ignition Test'. Proceedings of the Korea society of hazard mitigation conference, pp. 379-384

Kim Y. D., O. J. Choi, K. J. Kim, K. M. Kim, C. K. Hur and I. K. Cho 2005 'Component analysis of different parts of chestnut'. The Korean society of food preservation, No. 12(2): 156-160
Lee B. D., S. Y. Lee and J. S. Jung 2005 The behavior characteristics of the 2005 Yangyang forest fire'. Journal of the Korean institute of fire science and engineering, No. 19(4): 1-2

Lee, B. G. 2005 Introduction to forestry engineering. Youngnam University Publishing, pp. 57-87 (in Korea)

Lee K. S., Y. S. Choung, S. C. Kim, S. S. Shin, C. H. Ro and S. D. Park 2004 Development of vegetation structure after forest fire in the East coastal region. The Korean society of ecology and field biology, 27(2): 99-106

Lee S. Y., S. Y. Han, S. H. An, J. S. Oh, M. H. Jo and M. S. Kim 2001 'Regional Analysis of Forest Fire Occurrence Factors in Kangwon Province'. Korean Journal of Agricultural and Forest Meteorology, No. 3(3): 135-142

NFPA 9212011 Guide for fire \& explosion investigation, pp. 335348

Shin G. S. and W. Y. Ahn 1993 'Factors affecting the monoterpene composition in needles of Korean white pine (Pinus Koraiensis S. et Z.)'. Journal of the Korean society of wood science technology, No. 13(1): 44-51

Shim J. S., D. S. Shin, H. H. Lee, K. P. Lim, N. S. Cho and B. O. Cho 1994 Forest Chemistry. Hyangmoonsa, pp. 32-69 (in Korea)

Won M. S., K. S. Koo, M. B. Lee and Y. M. Son 2008 'Estimation of non- $\mathrm{CO}_{2}$ green house gas emissions from biomass burning in the Samcheok large-fire area using Landsat TMI magery'. Korean journal of agricultural and forest meteorology, No. 10. pp. $17-24$

Yim K. G. 2007 Forestation Theory. Hyangmoonsa, p. 47 (in Korea)

Kaufman, Y. J., C. J. Tucker and I. Y. Fung 1989 'Remote sensing of biomass burning in the tropics'. Advances in space research, No. 9(7): 265-268 